\title{
Diagnostic and Prognostic Value of Electromyographic Studies In Peripheral Nerve Injury
}

\author{
Gupta $P K,{ }^{1^{*}}$ Kotwal $P P_{,}{ }^{2}$ Bhatiya $M{ }^{3}$ Mittal $R,{ }^{4}$ Shrestha $N M^{5}$
}

\begin{abstract}
Affiliation:
1. Asst. Professor, Birat Medical College \& Teaching Hospital, Tankisinuwari-02, Morang, Nepal.

2. Professor, Department of Orthopaedics AIIMS, New Delhi.

3. Addl. Professor, Department of Neurology, AlIMS, New Delhi.

4. Addl. Professor, Department of Orthopaedics, AlIMS, New Delhi.

5. Lecturer, Birat Medical College \& Teaching Hospital, Tankisinuwari-02, Morang, Nepal.
\end{abstract}

\section{ARTICLE INFO}

\section{Article History}

Received : 27 July, 2016

Accepted : $14 \mathrm{Dec}, 2016$

Published : 20 Dec, 2016

(C) Authors retain copyright and grant the journal right of first publication with the work simultaneously licensed under Creative Commons Attribution License CC - BY 4.0 that allows others to share the work with an acknowledgement of the work's authorship and initial publication in this journal.

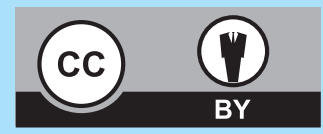

* Corresponding Author

Dr. Pradip Kumar Gupta Assistant Professor Department of Orthopedics

Birat Medical College \& Teaching Hospital

Tankisinuwari-02, Morang, Nepal

Email: pkgupta_22@yahoo.com

\section{Citation}

Gupta PK, Kotwal PP, Bhatiya M, Mittal R, Shrestha NM. Diagnostic and Prognostic Value of Electromyographic Studies in Peripheral Nerve Injury. BJHS 2016; 1(1) 1:65-70.

\section{ABSTRACT}

\section{Introduction}

Electro diagnostic studies provide the surgeons with critical information regarding the location, severity and nature of a nerve injury and also useful in predicting and assessing improvement during treatment either conservatively or surgically.

\section{Objective}

To evaluate the role of diagnostic and prognostic value of Electromyographic (EMG) studies in Peripheral Nerve injury.

\section{Methodology}

Fifty patients, having peripheral nerve injury were evaluated clinically and electro-physiologically to determine the role played by the latter in the management of such injuries. The study was prospective cohort study conducted at All India Institute of medical sciences, New Delhi.

\section{Results}

The most common mode of nerve injury was transection(54\%) and most common nerve involved was radial (38\%). The most common types of nerve injury in our study were axonotmesis $(42 \%)$. Nature of injury was evaluated clinically and electrophysiologically.

\section{Consclusions}

Electromyographic studies in peripheral nerve injury are helpful in diagnosing nerve injury, in localizing the site of injury and in estimating the extent of injury. EMG studies cannot give correct prognostic or quantify the functional recovery, but act as a useful modality to decide for re-exploration in operated cases.

\section{KEY WORDS}

Diagnostic \& prognostic value, electromyographic studies, peripheral nerve injury 


\section{INTRODUCTION}

The clinical manifestations of nerve injury in the initial stages may, in themselves give little clue to the type or severity of the nerve damage or the possibility of functional recovery. An understanding of pathophysiology of nerve damage and specific electrophysiological tests are the clinician's most important tools towards reaching to a correct diagnosis. ${ }^{1}$

Electro diagnostic studies provide the surgeons with critical information regarding the location, severity and nature of a nerve injury. They are also useful in predicting and assessing improvement during treatment either conservatively or surgically.

Electrophysiological studies are frequently indicated in nerve injuries to confirm the diagnosis, to help differentiate various clinical syndromes and to provide data to help decide about prognosis. The basic tools of these studies are the nerve conduction tests and electromyography. ${ }^{1}$ Nerve conduction tests are further divided into motor conduction and sensory conduction tests. ${ }^{2}$ These can be used to assess the number of functioning axons as well as the state of myelin thereby contributing much detail towards diagnosis and quantifying the extent of the lesion.The aim of this prospective cohort study evaluate the role of diagnostic and prognostic value of Electromyographic (EMG) studies in Peripheral Nerve injury

\section{METHODOLOGY}

Patients with peripheral nerve injury were enrolled in the study. Pre operative evaluation was done which included the history regarding onset, duration, timing. Anatomic location of the complaints were correlated with exercise, position and limb use. The patients were enquired about history of diabetes mellitus, acute infection, electrolyte disturbances, and uremia. A thorough clinical examination was done followed by electrophysiological studies. Sensory function

\section{TABLE 1: Frequency distribution of modes of injury $(n=50)$}

was tested over the autonomous zones (of individual nerves tested. The sensory assessment was made by touch, pain, and two-point discrimination test. ${ }^{3}$ For assessment of motor function the respective nerves were examined both above and below the injury site. The grading of motor power was done according to MRC scale.

The area of dry skin due to absence of sweating (Sudomotor Signs) was recorded. The vasomotor changes in the form of pallor, cyanosis, warm phase, and cold phase were noted. Reflexes in the area of nerve distribution were recorded. Hyposthesia and hyperesthesia were noted. Tinel's sign was elicited by fingertip or percussion hammer tap over the course of nerve.

Both motor and sensory conduction studies were done on Sapphire Premiere (Medlec, England) electromyographic machine. ${ }^{1}$

Motor nerve conduction study was estimated under stimulated thermal condition. Mostly surface electrodes were used sensory conduction studies were done by orthodromic stimulation. Needle electromyography (EMG) studydone to look neurogenic changes and evidence of active degeneration in the form of fibrillation. ${ }^{1}$

Nature of injury was classified on the basis of nerve conduction studies. ${ }^{4}$ The clinical and electrophysiological findings were compared with the findings at surgery (for patients warranting exploration) and six weeks later. The conduction velocities and needle electromyography studies were compared to the functional recovery in an attempt to correlate between the two. ${ }^{5}$

\section{RESULTS}

The most common cause of nerve injury in our study was transection (Knife cut, glass cut, stab injury, laceration and road traffic accident associated with fracture) i.e. 54\%. (Table 1.)

\begin{tabular}{|lcc|}
\hline \multicolumn{1}{|c}{ Mode of Injury } & Number & Percentage (\%) \\
\hline Transection & 27 & 54.0 \\
\hline Ischemia \& Compression & 7 & 14.0 \\
\hline Injection Injury & 6 & 12.0 \\
\hline Gunshot Injury & 4 & 8.0 \\
\hline Post Operated Fracture Fixation (Stretch, Traction \& Contusion) & 5 & 10.0 \\
\hline Electrical Injury & 1 & 2.0 \\
\hline
\end{tabular}




\section{Table 2: Frequency distribution of injury to individual nerves involvement}

\begin{tabular}{|lcc|}
\hline Nerve Involved & No. of Patients & Percentage (\%) \\
\hline Radial Nerve & 19 & 38.0 \\
\hline Ulnar Nerve & 17 & 34.0 \\
\hline Median Nerve & 7 & 14.0 \\
\hline Sciatic Nerve & 4 & 8.0 \\
\hline Common Peroneal Nerve & 2 & 4.0 \\
\hline Femoral & 1 & 2.0 \\
\hline
\end{tabular}

The most common nerve involvement in our study was radial (38\%). (Table 2)

\section{Table 3: Frequency distribution of nature of injury of the nerves}

\begin{tabular}{|lcc|}
\hline Nature of Injury & No. of Patients & Percentage (\%) \\
\hline Neuropraxia & 17 & 34.0 \\
\hline Axonotmesis & 21 & 42.0 \\
\hline Neurotmesis & 12 & 24.0 \\
\hline
\end{tabular}

The most common types of nerve injury in our study was Axonotmesis (42\%). (Table 3)

Nature of injury was evaluated clinically and also based on Nerve Conduction studies. Neuropraxia was diagnosed in patients who had normal or slightly reduced amplitude but significantly reduced velocity in conduction studies. Majority of patients in this study had a reduced conduction velocity as well as reduced amplitude suggesting partial Axonotmetic Neurotmetic injury.

In our study, 17 patients had Neuropraxia. Among them 14 patients were managed conservatively and 3 patients required surgery. Nature of surgery included neurolysis.

(Table 4)

\section{Table 4: Distribution of invovement of nerves neuropraxia type injury}

\begin{tabular}{|lccccc}
\hline Made of Injury & Radial & Ulnar & Median & Sciatic & Peroneal \\
\hline Compression & 4 & 1 & - & - & 1 \\
\hline Injection Injury & 3 & - & - & 2 & - \\
\hline Gun Shut Wound & 1 & - & - & 2 & - \\
\hline Post Operated\# Fixation & 2 & - & - & - & - \\
\hline Electrical Injury & - & - & 1 & - & - \\
\hline
\end{tabular}


Majority of patients in this study had a reduced conduction velocity as well as reduced amplitude suggesting partial axonotmetic- neurotmetic injury. There were 21 patients in this category and the mode of injury were. RTA with fractures and compression, laceration wounds and post operated fracture fixations. Among 21 patient 17 required surgery and 4 were managed conservatively. Nature of surgery included Excision of neuroma \& neurolysis done in 2 cases and suture in 15 cases. (Table 5).

\section{Table 5: Distribution of involvement of nerves in axonotmetic type injury}

\begin{tabular}{lcccccc} 
Mode of Injury & Radial & Ulnar & Median & Sciatic & Peroneal & Femoral \\
\hline Transection & 5 & 7 & 4 & 1 & - \\
\hline Post Op. \# Fixation & 2 & - & - & - & - \\
Post Injection & - & - & - & 1 & -
\end{tabular}

In our Study 12 patients had presented with neurotmetic injuries. Ten resulted from transection of nerve i.e. knife cut, glass cut and lacerations, and required suturing or nerve grafting while 2 patients had gunshot wounds and required nerve grafting (Cable nerve graft and Sural nerve graft) (Table 6)

The Electrophysiology parameters, Motor nerve conduction, Sensory nerve conduction and needle electromyography and motor functional recovery are shown in (table 7)

Electromyography (EMG) showed active degenerative changes (fibrillation) in $42 \%$ of patients pre-operatively \& $31.6 \%$ had chronic regenerative changes \& $26.33 \%$ had no active denervation \& reinnervation pre-operatively.

Six weeks after surgery needle EMG studies were performed and fibrillation potentials were found in denervated muscle, fibrillation and positive sharp waves were noted. In total denervation MUAP was not observed at all. The reinnervation after six weeks showed small \& high polyphasic potentials in $41.4 \%$ of operated patients \& $85.7 \%$ of patients treated conservatively. (Table 7)

Table 6: Distribution of involvement of nerve in neurotmetic injury

\begin{tabular}{lcccccc} 
Mode of Injury & Radial & Ulnar & Median & Sciatic & Peronea I & Femora \\
\hline Transection & - & 8 & 2 & - & - & - \\
\hline GSW & 2 & - & - & - & - & -
\end{tabular}

Table 7: Mean distribution of nerve conduction \& motor functional recovery

\begin{tabular}{|c|c|c|c|c|c|c|c|c|c|}
\hline \multirow[t]{2}{*}{$\begin{array}{l}\text { Type of Nerves } \\
\text { Injury }\end{array}$} & \multirow[t]{2}{*}{$\begin{array}{l}\text { Treatment } \\
\text { Option }\end{array}$} & \multicolumn{2}{|c|}{$\begin{array}{l}\text { Motor Conduction } \\
\text { Velocity (msec) }\end{array}$} & \multicolumn{2}{|c|}{$\begin{array}{l}\text { Motor } \\
\text { Function }\end{array}$} & \multicolumn{2}{|c|}{$\begin{array}{c}\text { Sensory } \\
\text { Conduction } \\
\text { Velocity (msec) }\end{array}$} & \multicolumn{2}{|c|}{$\begin{array}{l}\text { Motor } \\
\text { Function }\end{array}$} \\
\hline & & D1 & W6 & D1 & W6 & D1 & W6 & D1 & W6 \\
\hline \multirow[t]{2}{*}{ Neuropraxia } & Conservative & $45.9 \pm 5.9$ & $53.9 \pm 4.4$ & 2.0 & 3.0 & $30.5 \pm 5.9$ & $40.2 \pm 4.5$ & 1 & 2.5 \\
\hline & Operative & $43.3 \pm 6.1$ & $54.9 \pm 4.4$ & 2.0 & 3.0 & $27.1 \pm 6.2$ & $44.5 \pm 4.9$ & 1.7 & 2.9 \\
\hline \multirow[t]{2}{*}{ Axonotmesis } & Conservative & $19.5 \pm 7.1$ & $27.4 \pm 6.2$ & 1.0 & 2.0 & $20.1 \pm 6.9$ & $24.5 \pm 4$ & 1.0 & 1.5 \\
\hline & Operative & $22.1 \pm 8.2$ & $28.8 \pm 5.9$ & 1.2 & 2.9 & NR & NR & 0 & 1.0 \\
\hline Neurotmesis & Operative & NR & NR & 0 & 0 & NR & NR & 0 & 0 \\
\hline
\end{tabular}

D1 - Date of presentation, W6-Six week after presentation, NR-No response recorded 


\section{DISCUSSION}

With the advent of nerve conduction studies, quantification of the extent of damage and determination of the progression of regenerative mechanisms of the injured nerves have become possible. ${ }^{2,6}$ The preoperative conduction result could now be used as a baseline data to follow up patients postoperatively and quantify the functional recovery. Simple nerve conduction studies are helpful in assessment of recovery and this can, at times, obviate the need for an operation.

Nerve conduction studies have two variables the amplitude and latency. Conduction velocities can be calculated, taking into account the latency and the distance between electrode placements while stimulating from the two sites. ${ }^{7}$

Neuropraxia are the mildest form of nerve injury, being spontaneously reversible. There is a conduction block down the nerve fibres, and recovery takes place without Wallerian degeneration. ${ }^{4,8}$ Evidence suggests that ischemia is responsible for reversible nerve lesion and it is the mechanical distortion that is the major factor seen in long lasting forms of neuropraxia. In our series, a normal or slightly reduced amplitude and reduced velocity were seen in thirteen cases of neuropraxia. All of these cases improved and attained a motor power of grade III over a period of six weeks. Four cases having features of neuropraxia, improved after neurolysis and attained the motor power of graded III in six weeks.

Majority of nerve injuries do not transect or distract the nerve but leave it in gross continuity. Axonotmesis involves loss of continuity of axon and covering myelin sheath but still has an intact connective tissue framework. ${ }^{4,8}$ Since axonal continuity is lost, Wallerian degeneration ensures the commonest causes of axonotmesis include blunt trauma such as stretch, traction, contusion, transection (knife cut, glass cut, razor blade cut), road traffic accident associated with fracture and gunshot wound. Patients having no action potential distally about one week after the injury indicate complete axonotmesis. Whereas if there is conduction across the injury site, though with a low amplitude and velocity, it indicates partial axonotmetic injury. Preoperative findings in all the cases of this category revealed reduced velocity and amplitude. During surgery all the nerves were found in continuity and responded well to the surgical intervention as detected both clinically as well as electrophysiologically.

Soft tissue lacerations have the potential to transect the nerve. Such injuries are severe and have a poor recovery. Nerve injuries associated with lacerations should be considered as Neurotmetic until and unless proved otherwise. These injuries warrant urgent exploration. There were twelve cases of Neurotmetic injury in this study. Ten cases resulted from lacerations and two resulted from gunshot wounds. These had an absent evoked response distally at the time of the presentation.

Per-operatively, the nerves were found to be in discontinuity. Primary repair was carried out in 6 cases of laceration while six cases required nerve grafting.

Studies by Donoso, Ballantyne,and Hansen on the motor activity after nerve repair reported that motor activity was present in all the patients by ten months, which could be graded on MRC scale. ${ }^{5}$ Our study however revealed no voluntary motor activity in all cases within six weeks. The electrophysiological results also corresponded with the clinical findings. The recovery in the sensory nerve fibres was also poor. Mailender et al. and klinehave also reported better results in a long-term study. However, it was not really comparable since we had a very short follow-up in our study. ${ }^{9}$

In the present study we were able to classify our cases of nerve injuries depending upon the clinical as well as electro diagnostic methods.

In our study, the increase in the conduction velocity was found to have a direct correlation to the functional recovery. The results of the nerve conduction studies though are related to recovery, they cannot correctly quantify the functional improvement and thereby predicting the final function outcome after surgery in majority of these patients difficult.

In partial nerve injury, the needle EMG shows minimal "denervation potential" a considerable number of motor unit potentials (MUPs) with an increased proportion of polyphasic MUPs, and reduced recruitment of MUPs on maximal conduction. Conduction studies showed slow motor nerve conduction velocity (NCV), with decreased amplitude of muscle potential and absence of nerve potential or slow sensory NCV. In severe nerve injury, one observes failure to elicit any muscle potential with supramaximal stimulus, absence of nerve potential and numerous denervations potential with no MUP on maximal attempt at contraction in needle EMG.

Needle EMG study was performed after 6 weeks of surgery to assess the degree of regeneration. The reinnervation potential was noted to be complex. Frequently polyphasic potentials of longer duration and greater amplitude with reduction in the amount of fibrillation were seen. 
The operative results of nerve repair have improved with the advent of operating microscope, microsurgical instruments and superfine suture materials. ${ }^{10}$ It is now possible to carry out nerve repairs at the fascicular level. Intra-operative nerve conduction studies are being carried out now a day, which not only determine the site of injury but also are useful for planning out the nature and the extent of surgery.

\section{CONCLUSIONS}

Peripheral nerve injuries affect mainly the productive age group owing to more exposure of these patients to various hazards. Nerve conduction studies are an important diagnostic modality and help in the classification of peripheral nerve injuries. In every aspect of management of peripheral nerve injury, needle electromyography and nerve conduction velocity studies can give the clinician valuable objective information to supplement the clinical findings.
EMG studies in peripheral nerve injury are helpful in diagnosing nerve injury, in localizing the site of injury and in estimating the extent of injury. Needle EMG is most helpful in evaluation of the regeneration.

\section{LIMITATION OF THE STUDY}

This study cannot correctly give the prognostic value or quantify the functional recovery.

\section{ACKNOWLEDGEMENTS}

We are grateful to the participants in this study. We are also thankful to All India institute of Medical Sciences (AIIMS), New Delhi for creating platform to do this research.

\section{CONFLICT OF INTEREST}

No conflict of interest declared.

\section{REFERENCES}

1. Bralliar F: Electromyography: its use and misue in peripheral nerve injuries. Ortho clinic North-Am. 1981.A.P. 12 (2), 229-238.

2. Cragg BG and Thomas PK: Conduction velocity of regenerated peripheral nerve fibers; J Physio; 171: 164-175, 1964

3. Dellon A L: The moving two point discrimination test: clinical evaluation of the quickly adapting fibres / receptor system. J. Hand Surg; $3: 474,1978$

4. Seddan HJ: Three types of nerve injuries. Brain 66:238-288, 1943.

5. Ballantyne, J.P. and Campbell, M.J. Electrophysiological study after surgical repair of sectioned human peripheral nerves, J Neurol, Neurosurg and Psych. 1973; 36:797-805.
6. Erlanger J and Schoepfle GM: A study of nerve degeneration and regeneration. Am. J. Physio, 147; 550-581, 1946

7. Johnson EW, Olsen KJ: Clinical value of motor nerve conduction velocity determination. JAMA 1960; 172: 1-6.

8. Sunderland S: Nerves and nerve injuries, 2nd ed., Edinburgh, Churchill Livingstone, 1978

9. Kline DG, Hudson AR; Acute injuries of peripheral nerves. In Youmans Journal, Ed. Neurosurg, Philadelphia, WB Saunders 1990.

10. Seigel $D$ and Gelberman R: Median nerve: Applied anatomy and operative exposure. In Gelberman Red: Operative nerve repair and reconstruction. Philedelphia, JD Lippencott, 1991. 